\title{
HORIZONTES COMPREENSIVOS DA CONSTITUIC̣ÃO DO SER PROFESSOR DE QUÍMICA NO ESPAÇO DA PRÁTICA COMO COMPONENTE CURRICULAR: UM ESTUDO DE CASO
}

\author{
VIVIAN DOS SANTOS CALIXTO ${ }^{*}$ \\ https://orcid.org/0000-0002-5521-0633 \\ NEIDE MARIA MICHELLAN KIOURANIS" ** \\ https://orcid.org/0000-0002-1279-9994 \\ RUI MARQUES VIEIRA ${ }^{11}{ }^{* * *}$ \\ https://orcid.org/0000-0003-0610-6896
}

RESUMO: A determinação da inserção de 400h de Prática como Componente Curricular (PCC) nos cursos de formação de professores tem mobilizado espaços de discussão acerca da dimensão prática na constituição docente. Diante desse contexto, em nossa investigação tencionamos compreender a potencialidade da PCC no processo constitutivo do professor de Química. Para tanto desenvolvemos um estudo de caso em componentes curriculares com esta atribuição, constituindo informações por meio de materiais avaliativos produzidos pelos licenciandos, sendo as mesmas analisadas via pressupostos da Análise Textual Discursiva. Como compreensões emergentes destacamos: a relevância de compreender as percepções dos licenciandos acerca do que é ser professor como estratégia para complexificação de entendimentos superficiais e limitantes sobre a docência e dos processos atinentes ao ensinar e aprender.

Palavras-chave: Formação de professores. Prática como Componente Curricular Pensamento crítico.

\section{HORIZONTES COMPRENSIVOS DE LA CONSTITUCIÓN DEL SER PROFESOR DE QUÍMICA EN EL ESPACIO DE LA PRÁCTICA COMO COMPONENTE CURRICULAR: UN ANÁLISIS DE CASO}

RESUMEN: La decisión de inserir 400h de Práctica como Componente Curricular (PCC) en los cursos de formación de profesores ha movilizado espacios de debates acerca

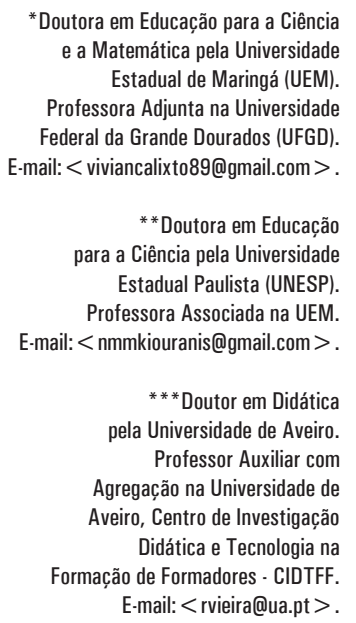

\footnotetext{
I Universidade Federal da Grande Dourados, Dourados, MS - Brasil.

II Universidade Estadual de Maringá, Maringá, PR - Brasil.

III Universidade de Aveiro, Centro de Investigação Didática e Tecnologia na Formação de Formadores, Aveiro - Portugal.
} 
del aspecto práctico en la constitución docente. Delante de ese contexto, en nuestra investigación pretendemos comprender la potencialidad de la PCC en el proceso constitutivo del profesor de Química. Para ello, desarrollamos un análisis de caso en componentes curriculares con esta atribución, constituindo informaciones por medio de materiales de evaluación elaborados por profesores en formación, y esas informaciones se analizaron a través de presupuestos del Análisis Textual Discursivo. Ponemos de relieve como comprensiones emergentes: la relevancia de comprender las percepciones de los maestros en formación acerca de lo que es ser profesor como estrategia de tornar complejos entendimientos superficiales y limitativos sobre la docencia y de los procesos relativos a enseñar y aprender.

Palabras clave: Formación de profesores. Práctica como Componente Curricular. Pensamiento crítico.

\section{UNDERSTANDING HORIZONS OF THE CONSTITUTION OF BEING A CHEMISTRY TEACHER IN PRACTICE AS A CURRICULAR COMPONENT: A CASE STUDY}

ABSTRACT: The determination of the insertion of $400 \mathrm{~h}$ of Prática como Componente Curricular (PCC) in teacher training courses has mobilized spaces for discussion about the practical dimension in teacher constitution. Given this context, in our investigation we intend to understand the potentiality of the CCP in the constitutive process of the chemistry teacher. Therefore, we developed a case study in curricular components with this assignment, constituting information through evaluative materials produced by the undergraduates, which are analyzed through the assumptions of Discursive Textual Analysis. As emerging understandings we highlight: the relevance of understanding undergraduates' perceptions of what it is to be a teacher as a strategy for complexifying superficial and limiting understandings about teaching and the processes related to teaching and learning.

Keywords: Teacher training. Prática como Componente Curricular. Critical thinking. 


\section{PRIMEIRAS PALAVRAS}

Os cursos de formação de professores, no contexto brasileiro, vêm experienciando, no decorrer das últimas décadas, uma série de movimentos de reestruturação, determinados via documentos normativos. Como exemplo desse processo podemos citar a proposição da inserção de $400 \mathrm{~h}$ de Prática como Componente Curricular (PCC) reforçada na Resolução 2/2015 (BRASIL, 2015). Por meio dessa determinação, contemplada inicialmente na Resolução CNE/CP 2, de 19 de fevereiro de 2002, Brasil (2002), e reforçada na última Resolução, os elaboradores dos currículos foram desafiados a repensar a organização de propostas para alocação desta carga horária no decorrer da matriz curricular dos cursos de formação de professores.

Diante dessa conjectura, as investigações com foco na organização curricular dos cursos de licenciatura têm relatado, analisado e problematizado, em diversas publicações, a existência de múltiplos formatos de implementação da carga horária de PCC (KASSEBOEHMER e FARIAS, 2012; ALMEIDA, 2016; PEREIRA e MOHR 2017; MARTINS e WENZEL, 2017). De forma geral as possibilidades de incorporação no currículo, descritas nas pesquisas, seguem duas orientações: a) inserção da carga horária de PCC à componentes já existentes no currículo e; b) criação de novos componentes com a intencionalidade de atender esta demanda.

Como compreensões emergentes das investigações, com foco na PCC, são destacadas: sua potencialidade enquanto elemento de problematização e rompimento para com organizações curriculares atreladas a princípios da racionalidade técnica; na promoção da indissociabilidade entre teoria e prática; no desenvolvimento de cursos com uma identidade mais bem definida, ou seja, com maior foco na formação do professor; na sua capacidade em oportunizar o desenvolvimento de um maior isomorfismo entre a formação ofertada e a exigida; na complexificação do espectro de compreensão da dimensão prática da ação docente, e; a polissemia atrelada aos entendimentos sobre a mesma (KASSEBOEHMER e FARIAS, 2012; SILVÉRIO, 2014; ALMEIDA, 2016; MARTINS e WENZEL, 2017; PEREIRA e MOHR, 2017; MOHR e WIELEWICKI, 2017; CALIXTO, 2019).

Ante o exposto, nesse texto abordaremos algumas das compreensões emergentes, vinculadas a uma investigação mais ampla (CALIXTO, 2019), acerca da constituição do ser professor de química no espaço da PCC. Como objetivo tencionamos compreender, via desenvolvimento de um estudo de caso, o processo de constituição do ser professor de química no contexto de um componente com carga horária integral de PCC.

\section{A DIMENSÃO PRÁTICA NA AC̣ÃO DOCENTE: A PRÁTICA COMO COMPONENTE CURRICULAR E O PENSAMENTO CRÍTICO COMO ELEMENTOS POTENTES NA SUA COMPLEXIFICAC̣ÃO}

A dimensão prática na ação docente vem sendo foco de discussão, tanto quando consideramos o contexto dos documentos normativos, quanto as pesquisas na área de formação de professores. Nesse ínterim, a relevância da construção de currículos orientados por princípios como a indissociabilidade 
entre teoria e prática e que prezem por um isomorfismo entre a formação ofertada e a exigida, vem sendo ponto de convergência na construção de argumentos de diferentes autores (MARCELO-GARCÍA, 1999; KASSEBOEHMER e FARIAS, 2012; MOHR e WIELEWICKI, 2017; CUNHA, 2018).

Com a determinação de inserção da carga horária de PCC, via documentos normativos, nos cursos de licenciatura, emerge um contexto frutífero para análise e problematização do princípio da indissociabilidade entre teoria e prática no percurso constitutivo do ser professor. Nestes documentos pode ser observado um exercício, constante e progressivo, no intento de promover uma complexificação do entendimento da dimensão prática na ação docente, concretizando esse movimento via proposição da inserção de uma carga horária mínima desta dimensão, de forma a ampliar a gama de possibilidades de organização desta nuance no currículo (DINIZ-PEREIRA, 2011; MOHR e WIELEWICKI, 2017).

Desde sua determinação inicial vem sendo realizado um exercício de redação, nos documentos, pareceres e resoluções, que promova uma distinção das ações propostas na PCC das realizadas nos Estágios. Porém, o argumento da necessária articulação dos saberes e ações desenvolvidos nesses contextos se mantém constante (DINIZ-PEREIRA, 2011).

Autores como Barbosa e Cassiani (2014) ao analisarem os documentos normativos, com foco na PCC, argumentam que os mesmos agregam em suas compreensões os resultados de pesquisas do campo da formação de professores, tais como a articulação entre teoria e prática e a aproximação entre a Universidade e a Escola. Cabe ressaltar que a discussão da PCC emerge em um contexto de valorização do modelo da racionalidade prática, no qual em sua essência valoriza a cultura reflexiva e mobiliza o movimento de profissionalização do ensino, emergente na década de 1980.

Diante desse contexto o discurso empregado nos documentos normativos, acerca da PCC, emprega muitas das argumentações tecidas no modelo de formação de professores centrado na racionalidade prática (BARBOSA e CASSIANI, 2014). Ante essa percepção precisamos considerar as críticas tecidas a este modelo, utilizando-as como fonte para um movimento de problematização das ações desenvolvidas no lócus da PCC.

As discussões de autores como Pimenta (2006) e Zeichner (2013) são potentes nesse processo, pois oportunizam reflexões coerentes e problematizações significativas acerca deste modelo, especialmente, quando mencionam: a confusão atrelada ao termo reflexão, que em muitas situações é percebido como mero adjetivo e não como conceito, desconsiderando os princípios envolvidos; supervalorização da prática, suprimindo a importância da teoria no desenvolvimento dos saberes inerentes à docência; entendimento da reflexão como único fator para resolução de problemas da prática; desconsideração do Outro no processo reflexivo, reduzindo-o a uma ação individualizada, e; a depreciação da importância da teoria como aliada e indissociável da prática, na intenção de resolver problemas provenientes das ações cotidianas do professor.

Nesse ínterim o planejamento, análise e avaliação de materiais didáticos vem sendo destacados como exercícios potentes nas ações vinculadas a PCC. 
Pereira e Mohr (2017), ao argumentarem sobre a relevância de ampliarmos nossa compreensão da dimensão prática na ação docente, atribuem a atividades, como as envolvidas no planejamento, a função prática. Carvalho e Gil-Pérez (2011) e Cunha (2018) também corroboram desse entendimento.

Diante dessa conjectura a proposição da elaboração de planejamentos orientados para promoção do pensamento crítico (PC), no espaço de componentes curriculares com carga horária integral de PCC, assume uma potencialidade relevante, visto que oportuniza o desenvolvimento de saberes docentes acerca do planejamento e que busquem se ancorar em princípios como a indissociabilidade entre teoria e prática.

Ante o exposto, compreendemos que o desenvolvimento de propostas, que incorporem esses princípios, pode se fortalecer quando implementam discussões correlatas ao ensino do PC. Distintos autores têm argumentado acerca da potencialidade que a inserção de discussões concernentes ao PC, na formação de professores, pode assumir quando princípios como a indissociabilidade entre teoria e prática e o isomorfismo entre a formação ofertada e a exigida estão em foco (TENREIRO-VIEIRA, 2000; VIEIRA, 2003).

As discussões concernentes ao PC, no contexto educacional, emergem de forma mais intensa no final da década de 1980, do século XX. Dentre os autores que têm em seu escopo de discussão essa nuance destacam-se Ennis (1987); Halpern (1989); Paul e Elder (2008); Tenreiro-Vieira, 2000 e Vieira, 2003. Sendo Ennis o responsável pelo desenvolvimento de uma taxonomia do PC, situação que o configura como um dos autores mais utilizados em investigações no contexto educacional.

Halpern define o PC como um tipo de pensamento racional e intencional, centrado em processos que envolvam a resolução de problemas e tomada de decisões. Argumenta que o seu desenvolvimento oportuniza a formação de cidadãos aptos a tomar decisões que envolvam sua vida no planeta Terra, porém elucida que o sistema educacional não desenvolve ações que possibilitem isso. A autora ainda complementa discorrendo que a palavra crítico tem atribuída a si, de forma recorrente, um sentido negativo, mas devemos construir sentidos que a aproximem de um processo de avaliação pois quando realizamos ações que promovem um exercício de avaliação de nosso pensamento, tomada de decisão e resolução de problemas, estamos pensando criticamente (HALPERN, 1989).

Autores como Paul e Elder argumentam que o PC se configura como a arte de pensar sobre o pensamento, buscando assim estratégias para modificá-lo e com isso melhorá-lo. Destacam a existência de dois tipos de PC, forte e fraco, sendo o fraco caracterizado por uma forma de pensar monológica, constituída por um único ponto de vista. Enquanto o forte se caracteriza por outro movimento, ou seja, constituído por diferentes pontos de vista, dialógico (PAUL e ELDER, 2008).

Para Robert Ennis, o PC trata-se de um tipo de pensamento de ordem superior, ou seja, requer consciência para sua aplicação. Exige habilidades como autodeterminação, reflexão, esforço, autocontrole e metacognição (ENNIS, 1987). Define o PC como uma atividade prática e reflexiva, organizando-o a partir de cinco termos, dos quais podemos destacar: reflexivo, sensato, prático, crença e ação (ENNIS, 1996). Nesse sentido, podemos configurar o PC como uma forma de pensar racionalmente que envolve reflexão centrada em analisar sobre como agir. 
Nos ancorando nas discussões tecidas pelos autores supracitados, e mais intensamente nas contribuições de Ennis, Tenreiro-Vieira e Viera, compreendemos que o PC se configura como um saber em ação, que oportuniza olhar e problematizar a realidade, considerando suas múltiplas facetas, para então ter a oportunidade de transformá-la. Sendo assim, ao desafiar os licenciandos a elaborar planejamentos orientados para promoção do PC oportuniza-se o desenvolvimento de saberes correlatos ao ensino e a aprendizagem, as diferentes metodologias e a constante aproximação entre o pensar e o fazer na ação docente.

\section{PROPOSTA METODOLÓGICA}

Nossa investigação assume uma ênfase qualitativa com o desenvolvimento de um estudo de caso do tipo único integrado (YIN, 2015). Segundo o autor "um estudo de caso investiga um fenômeno contemporâneo (o "caso") em seu contexto no mundo real, especialmente quando as fronteiras entre o fenômeno e o contexto puderem não estar claramente evidentes" (2015, p. 2).

Nesse sentido, ancorados nas discussões de Yin (2015), compreendemos que nossa pesquisa assumiu uma abordagem qualitativa e pode se configurar como um estudo de caso de tipo dois, ou seja, um estudo de caso único integrado. Pois pertence a um único contexto, o curso de Licenciatura em Química (BRASIL, 2017), centra-se na investigação de um único caso, constituído pelo grupo de seis alunos que cursaram os três componentes curriculares, foco da investigação, o que oportunizou a constituição de três unidades de análise. Ou seja, uma para cada componente curricular.

Compreendemos que o caso, ou seja, o fenômeno contemporâneo, delineia-se na constituição do ser professor de Química, de um grupo de seis alunos do curso de Licenciatura em Química da região Centro-Oeste do Brasil, mediante o desenvolvimento de ações que objetivavam a elaboração de um planejamento orientado para a promoção do PC, por parte dos licenciandos, como estratégia para o desenvolvimento de uma crítica fundamentada ao ensino por transmissão, ao longo de três componentes curriculares com carga horária integral de PCC. Sendo que nesse artigo nos restringiremos a abordar as compreensões emergentes da análise de um dos componentes curriculares investigados, ou seja, o de Bases Teóricas para a Aprendizagem I (BTA I). ${ }^{1}$

Como informações empíricas foram selecionados os materiais avaliativos dos licenciandos que cursaram o componente de BTA I, ou seja, os portfólios e os planos de aula. No total seis licenciandos participaram da investigação, e como cada um deveria elaborar um portfólio tivemos um total de seis portfólios. à medida em que as aulas prosseguiam, escritas reflexivas eram solicitadas aos licenciandos. No intento de facilitar o processo de escrita, questões problematizadoras eram propostas, com a intencionalidade de catalisar o processo. Cada portfólio deveria conter, aproximadamente, sete escritas. No que se refere aos planos de aula, os mesmos foram elaborados em dupla, logo tivemos um total de três planos de aula.

O Quadro 1, na sequência, apresenta as temáticas e questões catalizadoras que orientaram o processo de escrita dos Portfólios. 
QUADRO 1. Organização e temáticas das escritas do portfólio de BTA I

\begin{tabular}{|c|c|}
\hline $\begin{array}{l}\text { Número da } \\
\text { Escrita }\end{array}$ & Foco da escrita \\
\hline E1 & $\begin{array}{l}\text { Individual - } 0 \text { que é ser Professor de Química? } 0 \text { que é PC? Que } \\
\text { estratégias podem ser desenvolvidas para promover o PC? }\end{array}$ \\
\hline E2 & $\begin{array}{l}\text { Coletiva - Dinâmica de análise da E1 e elaboração da síntese coletiva } \\
\text { durante a aula }\end{array}$ \\
\hline E3 & $\begin{array}{l}\text { Individual - Construa um texto a partir dos seguintes questionamentos: } \\
0 \text { que é epistemologia? } \\
\text { Qual a diferença entre modelo pedagógico e epistemológico? } \\
\text { Defina o que é informação e o que é conhecimento? } \\
\text { Baseado nas discussões realizadas ao longo da aula escreva } \\
\text { um pequeno texto expondo suas opiniões acerca do estudo da } \\
\text { Epistemologia na formação de professores }\end{array}$ \\
\hline E4 & $\begin{array}{l}\text { Em dupla - } 0 \text { que a aula sobre PC me fez pensar sobre o Seminário? } 0 \\
\text { que aprendi? }\end{array}$ \\
\hline E5 & $\begin{array}{l}\text { Individual - A partir do que estudamos até o momento acerca da } \\
\text { abordagem Tradicional, podemos argumentar que esta perspectiva } \\
\text { oportuniza a promoção de capacidades de PC? }\end{array}$ \\
\hline E6 & $\begin{array}{l}\text { Individual - Construa uma narrativa onde apresentas como seria } \\
\text { uma sala de aula ancorada na teoria Behaviorista, lembre-se de } \\
\text { pontuar como seria a relação Ensino/Aprendizagem e Professor/ } \\
\text { Aluno, a metodologia e avaliação utilizadas. Além de destacar se esta } \\
\text { abordagem oportuniza ou não a promoção de capacidades de PC. }\end{array}$ \\
\hline E7 & $\begin{array}{l}\text { Individual - Escreva uma carta direcionada a uma escola e por } \\
\text { decorrência a um grupo de professores, argumentando acerca dos } \\
\text { limites e potencialidades com o trabalho orientado a partir de uma } \\
\text { abordagem humanista. Lembre-se de pontuar como ocorre: o ensino } \\
\text { e a aprendizagem; a relação professor e aluno; a metodologia; a } \\
\text { avaliação; Promoção do PC. }\end{array}$ \\
\hline
\end{tabular}

Fonte: Os próprios autores.

A análise do material empírico ocorreu via pressupostos teóricos e metodológicos da Análise Textual Discursiva, a qual se estrutura por meio de quatro focos, dos quais se destacam: desmontagem dos textos, estabelecimento de relações, captando o novo emergente e um processo auto-organizado (MORAES e GALIAZZI, 2016). O primeiro movimento se centra no processo de unitarização, ou seja, a elaboração das unidades de significado, posteriormente nos centramos na categorização e concluímos o processo de análise via elaboração do metatexto. 
Sendo que o metatexto constitui-se por um processo de ancoragem das unidades de significados, das teorias emergentes da análise e das compreensões construídas pelo pesquisador (MORAES e GALIAZZI, 2016). Neste texto apresentaremos o metatexto de análise intitulado: "O delineamento de um horizonte compreensivo: o processo de constituição do ser professor de Química no espaço de um componente com carga horária integral de PCC”, que se constitui pelas categorias intermediárias: "Ser professor de Química: um contínuo exercício de aprender e articular saberes" e "Estratégias que intencionem promover o PC e o perfil de pensador crítico que se almeja: uma relação necessária”. Na sequência, o Quadro 2 contempla o processo de categorização que oportunizou a emergência das categorias supracitadas.

QUADRO 2. Processo de categorização das escritas dos Portfólios do componente de BTA I

\begin{tabular}{|c|c|c|c|c|c|}
\hline $\begin{array}{l}\text { Cat. } \\
\text { Inicial }\end{array}$ & $\begin{array}{c}\text { Cat. } \\
\text { Inicial } \\
\text { Argumento }\end{array}$ & $\begin{array}{c}\text { Cat. } \\
\text { Intermediária }\end{array}$ & $\begin{array}{c}\text { Cat. } \\
\text { Intermediária } \\
\text { Argumento }\end{array}$ & $\begin{array}{l}\text { Cat. } \\
\text { Final }\end{array}$ & $\begin{array}{c}\text { Cat. Final } \\
\text { Argumento }\end{array}$ \\
\hline $\begin{array}{l}\text { A - Ser } \\
\text { professor } \\
\text { de Química }\end{array}$ & $\begin{array}{l}\text { Ser professor de } \\
\text { Química envolve um } \\
\text { processo contínuo } \\
\text { de formação, bus- } \\
\text { cando articular os } \\
\text { diferentes saberes } \\
\text { que compõem sua } \\
\text { área }(7)^{2}\end{array}$ & \multirow[t]{2}{*}{$\begin{array}{l}A+C=(7+2)=9 \\
\text { Ser professor } \\
\text { de Química: um } \\
\text { contínuo exercí- } \\
\text { cio de aprender } \\
\text { e articular } \\
\text { saberes }\end{array}$} & \multirow{2}{*}{$\begin{array}{l}\text { Ser professor } \\
\text { de Química } \\
\text { constitui- } \\
\text {-se por um } \\
\text { processo } \\
\text { contínuo de } \\
\text { formação } \\
\text { considerando } \\
\text { a relevância } \\
\text { de articular } \\
\text { os diferentes } \\
\text { saberes que } \\
\text { compõem o } \\
\text { seu exercício } \\
\text { profissional } \\
\text { e a relação } \\
\text { com seus } \\
\text { alunos }\end{array}$} & \multirow{5}{*}{$\begin{array}{l}0 \text { delinea- } \\
\text { mento de um } \\
\text { horizonte } \\
\text { compre- } \\
\text { ensivo: o } \\
\text { processo de } \\
\text { constitui- } \\
\text { ção do ser } \\
\text { professor de } \\
\text { Química no } \\
\text { espaço de um } \\
\text { componente } \\
\text { com carga } \\
\text { horária inte- } \\
\text { gral de PCC } \\
\text { (31) }\end{array}$} & \multirow[t]{5}{*}{$\begin{array}{l}\text { Ser pro- } \\
\text { fessor de } \\
\text { Química se } \\
\text { constitui por } \\
\text { um constan- } \\
\text { te aproximar } \\
\text { e ampliar } \\
\text { realidades }\end{array}$} \\
\hline $\begin{array}{l}\text { C - Pro- } \\
\text { cesso de } \\
\text { ensinar e } \\
\text { aprender } \\
\text { envolve }\end{array}$ & $\begin{array}{l}\text { Os processos de } \\
\text { ensinar e aprender } \\
\text { englobam a relação } \\
\text { professor e aluno } \\
\text { (2) }\end{array}$ & & & & \\
\hline $\begin{array}{l}\text { B - Perfil } \\
\text { do Pensa- } \\
\text { dor Crítico }\end{array}$ & $\begin{array}{l}0 \text { perfil do pensa- } \\
\text { dor crítico envolve } \\
\text { autoquestionamen- } \\
\text { to e curiosidade (6) }\end{array}$ & \multirow{3}{*}{$\begin{array}{l}\mathrm{B}+\mathrm{D}+\mathrm{F}= \\
(6+14+2)=22 \\
\text { Estratégias que } \\
\text { intencionem } \\
\text { promover o PC } \\
\text { e o perfil de } \\
\text { pensador crítico } \\
\text { que se almeja: } \\
\text { uma relação } \\
\text { necessária }\end{array}$} & \multirow{3}{*}{$\begin{array}{l}\text { As estra- } \\
\text { tégias que } \\
\text { intencionem } \\
\text { promover o } \\
\text { PC devem } \\
\text { estar ancora- } \\
\text { das ao perfil } \\
\text { de pensador } \\
\text { crítico que } \\
\text { objetivasse } \\
\text { desenvolver }\end{array}$} & & \\
\hline $\begin{array}{l}\text { D - As es- } \\
\text { tratégias } \\
\text { promoto- } \\
\text { ras do PC }\end{array}$ & $\begin{array}{l}\text { As estratégias que } \\
\text { objetivam promover } \\
\text { o PC englobam } \\
\text { debates, questiona- } \\
\text { mento, resolução } \\
\text { de problemas e } \\
\text { tomada de decisão } \\
\text { (14) }\end{array}$ & & & & \\
\hline $\begin{array}{l}\text { F - Teorias } \\
\text { da Apren- } \\
\text { dizagem } \\
\text { e PC }\end{array}$ & $\begin{array}{l}\text { Pensar como as te- } \\
\text { orias da aprendiza- } \\
\text { gem se relacionam } \\
\text { ao desenvolvimento } \\
\text { do PC é relevante e } \\
\text { importante (2) }\end{array}$ & & & & \\
\hline
\end{tabular}

Fonte: Os próprios autores. 


\section{O DELINEAMENTO DE UM HORIZONTE COMPREENSIVO: O PROCESSO DE CONSTITUICCÃO DO SER PROFESSOR DE QUÍMICA NO ESPAC O DE UM COMPONENTE COM CARGÁ HORÁRIA INTEGRAL DE PCC}

O processo de análise nos oportunizou vislumbrar algumas das pistas inerentes à constituição do ser professor de Química no componente curricular de BTA I, foco do estudo de caso. Dentre elas, destaca-se a relevância de compreender as percepções dos licenciandos acerca do que é ser professor, como estratégia para complexificação de entendimentos superficiais e limitantes sobre a docência e dos processos atinentes ao ensinar e aprender. Assim como, da relevância da articulação profícua entre a orientação e a operacionalização das estratégias de ensino, ou seja, dos seus princípios fundantes para com seu desenvolvimento.

\section{SER PROFESSOR DE QUÍMICA: UM CONTÍNUO EXERCÍCIO DE APRENDER E ARTICULAR SABERES}

O componente curricular de BTA I, foco do estudo de caso, localiza-se no segundo semestre do curso. Nesse sentido, os licenciandos ainda estão na primeira metade do processo formativo e constituem-se por muitos questionamentos, incertezas e, de certa forma, uma imaturidade, relativamente significativa, no que se refere a estar em um curso de graduação. Não que nos alunos pertencentes a segunda metade do curso inexistam essas características, mas não de forma tão acentuada quanto nos iniciantes.

Diante desse contexto, as primeiras ações elaboradas nesse componente objetivaram compreender as visões sobre ser professor desses licenciandos, ou seja, que compreensões permeiam o imaginário destes futuros profissionais da educação. Por meio da análise das escritas dos portfólios foi possível a emergência de entendimentos mais simplistas e carregados por representações que cotidianamente são reforçadas na sociedade, mas também foram apresentados outros mais complexos e carregados por um sentido atrelado ao processo de profissionalização docente.

Permearam as compreensões sobre ser professor pelo menos duas nuances, das quais podemos citar: a percepção do processo contínuo de formação e a relevância da articulação dos saberes específicos e pedagógicos. Por meio dessas duas nuances outros desdobramentos foram expostos como a didática dos professores, o interesse dos alunos e a desvalorização da carreira docente.

Sobre a percepção do professor como um profissional em permanente processo de formação, a licencianda $A Q$ salienta que o mesmo precisa estudar constantemente e tem como papel mediar a escolha profissional de seus alunos, nas suas palavras:

Ser professor é passar conhecimento apesar de estar estudando constantemente, em química ainda mais, pois além da sala de aula, bá o laboratório, que é o lugar que eu acho que o aluno é mais instigado a aprender química. O professor também é o mediador a ajudar o aluno a escolher sua profissão [AQE1.1]. ${ }^{3}$ 
Alguns pontos podem ser problematizados a partir da escrita da licencianda, o primeiro deles se refere ao fato de atribuir ao professor o papel de passar conhecimento. Uma concepção de ensino por transmissão pode estar alicerçando essa afirmação, sendo assim, é importante que os professores do curso de licenciatura busquem problematizar essas percepções e ampliar as compreensões inerentes aos processos de ensinar e aprender.

A ampla maioria dos licenciandos ingressantes no curso utiliza termos e expressões vinculadas a perspectivas transmissivas de ensino e aprendizagem, orientadas por um pressuposto de Educação Bancária, como por exemplo: passar, transferir e transmitir. Nesse sentido, delinear os pressupostos que orientam essas perspectivas parece ser o ponto inicial para problematizá-las. Compreender o que entendemos por aprender pode se configurar como elemento relevante no percurso que visa compreender o que é ensinar.

Quando utilizamos o termo Educação Bancária, para tratar de um ensino transmissivo, nos ancoramos na definição desenvolvida por Freire (2016, p. 105), crítico ferrenho dessa orientação, argumenta que nela "o saber é uma doação dos que se julgam sábios aos que julgam nada saber". O autor ainda complementa "se o educador é o que sabe, se os educandos são os que nada sabem, cabe àquele dar, entregar, transmitir o seu saber aos segundos. Saber que deixa de ser de 'experiência feita' para ser de experiência narrada ou transmitida” (ibidem, p. 107).

Em parte, a concepção de ensino por transmissão, observada na escrita dos licenciandos, é proveniente das experiências que muitos têm enquanto alunos, nas quais não vivenciaram ou mesmo não reconhecem episódios de ensino que oportunizam a eles ter voz e ação em sala de aula. Diante desse contexto, problematizar as concepções acerca do ensinar e aprender, que envolvem as práticas pedagógicas, se demonstra como fator essencial na busca por tecer críticas consistentes e que façam sentido para os licenciandos, no que se refere ao ensino por transmissão.

Além de promover espaços que abordem os modos de ensinar e aprender, contemplados nas teorias da aprendizagem, ao longo da formação inicial, Quadros et al (2005) argumentam sobre a potencialidade de trabalhar a partir das memórias que os licenciandos têm de seus professores, ou seja, dos modelos de professor que constroem, considerando os distintos níveis de escolarização, como meio para problematizar concepções alicerçadas no ensino transmissivo.

Esse "modelo" de professor descrito pelos autores, se vincula ao que Carvalho e Gil-Pérez (2011) denominam de pensamento docente espontâneo, sendo este desenvolvido pelos licenciandos a partir dos inúmeros anos de vivência na sala de aula, enquanto alunos. Diante desse cenário, ações que objetivem problematizar e complexificar modelos de professor e de ensino e aprendizagem que se orientem por processos transmissivos, pautados na educação bancária, podem ser potencialmente significativas quando contemplam discussões acerca de aspectos que envolvam o ensinar e o aprender, assim como análise crítica de vivências destes licenciandos ao longo do seu percurso escolar.

Outro ponto a ser destacado da escrita da licencianda AQ se refere a perpetuação de uma representação da química como ciência difícil e para poucos, pode-se notar que a mesma sinaliza "em química ainda mais", como se a química fosse uma área mais árdua do que outra. É o constante exercício de reprodução 
do discurso de supervalorização das ciências exatas em detrimento das humanas. Nesse contexto, cria-se uma realidade na qual a química é considerada mais difícil do que outras áreas e por meio da propagação desse discurso que, mesmo que não consciente, tende-se a desvalorizar outros campos do conhecimento.

O mesmo raciocínio pode ser desenvolvido quando pensamos no processo de desvalorização da carreira docente, historicamente esta vem sendo destacada em um discurso de depreciação, quando comparada a outras. Cria-se assim uma realidade na qual ser professor é "bico", segunda opção ou vocação, estas ênfases delineiam um horizonte em que ser professor não repercute em valorização profissional.

Compreendemos como pertinente, dentro do exposto, entender o conceito de realidade e suas formas de perpetuação. Este vem sendo amplamente estudado no campo da psicanálise e tenciona compreender a relação entre sujeito e o exterior a ele. Berger e Luckmann (2002, p. 11) argumentam que a realidade é socialmente construída e pode ser definida como "qualidade pertencente a fenômenos que reconhecemos terem um ser independente da nossa própria volição" e se perpetua pela corporificação de rotina, que é a essência da institucionalização.

A realidade pode ser caracterizada como objetiva e subjetiva e passa constantemente por processos de socialização, que podem se dividir em dois níveis: primário e secundário. Sendo que a realidade objetiva se configura como aquela institucionalmente definida, enquanto a subjetiva apreendida na consciência individual. O processo de socialização jamais é completo, os conteúdos que interioriza estão constantemente ameaçados pela realidade subjetiva. Nesse sentido, precisam ser realizados procedimentos para conservação da realidade, preservando um certo grau de simetria entre a realidade objetiva e subjetiva (BERGER e LUCKMANN, 2002).

Os mesmos autores atribuem à conversa o mais importante papel na conservação da realidade, argumentam que podemos "considerar a vida cotidiana do indivíduo em termos do funcionamento de um aparelho de conversa, que continuamente mantém, modifica e constrói sua realidade subjetiva" (BERGER e LUCKMANN 2002, p. 202). Ampliam pontuando que a fração mais representativa da conservação da realidade na conversa ocorre de forma implícita, "a maior parte da conversa não define em muitas palavras a natureza do mundo. Ao contrário, ocorre tendo por pano de fundo um mundo que é tacitamente aceito como verdadeiro" (BERGER e LUCKMANN, 2002, p. 203).

Ante o exposto, como formadores de professores, precisamos considerar o conjunto de fatores que corroboram com a conservação e fortificação da realidade descrita pelos licenciandos acerca da profissão professor. Não basta apresentar um apanhado de autores e teorias que justificam a relevância da valorização da carreira docente, sem que este processo de problematização possa ser significante o suficiente para mobilizar a estrutura subjetiva da realidade e posterior modificação da objetiva, desestabilizando assim a simetria entre ambas.

A compreensão do processo de profissionalização docente precisa estar constituída por práticas que façam sentido e desenvolvam significados para os licenciandos, isso só poderá ocorrer quando no próprio curso de formação sejam oportunizados espaços para tal. É nesse cenário que a PCC e o Estágio assumem um papel de extrema importância e se configuram como potência na constituição 
de professores com um nível mais elevado de pertencimento para com sua área de atuação e que lutem pela profissionalização e valorização da carreira docente.

Ainda sobre a unidade de significado, referente à escrita de AQ, chamanos a atenção a atribuição destinada ao professor como mediador no processo de escolha profissional de seus alunos. A maioria dos licenciandos que entra no curso, querendo ser professor, o faz por embasamento em uma boa experiência com um professor de Química, tal como evidencia o estudo de Quadros et al (2005).

Estes autores ao entrevistaram trinta e seis acadêmicos, que estavam cursando os dois últimos semestres de um curso de Licenciatura em Química, afirmam que pelo menos metade destes sinalizaram explicitamente a influência dos professores, que tiveram ao longo do processo de escolarização, na sua escolha profissional (QUADROS et al, 2005). Sendo esta baseada em alguns aspectos, dos quais citam: afetivos, pedagógicos ou de conhecimento. A dimensão afetiva contempla a relação professor-aluno, a pedagógica a aspectos inerentes ao ensino e a aprendizagem e a de conteúdo ao domínio de conhecimento do professor. Segundo a pesquisa, a dimensão mais recorrente foi a pedagógica.

Alguns dos pontos sinalizados a partir da escrita da licencianda AQ também são corroborados pela licencianda KP, tais como a concepção do processo de ensinar como sinônimo de transmissão, além do reforço da característica da química como ciência exata, constituída por verdades inquestionáveis e por uma intensa dificuldade no seu fazer. No entanto, outras nuances são elucidadas como a relevância de o professor ter o que ela chama de "boa didática". Ao professor também é atribuída a relevância de apresentar domínio da matéria para com isso desenvolver o interesse dos alunos, em suas palavras:

A química é uma ciência exata e para ser um bom professor de química é necessário ter o domínio da
matéria, para passa-la para seus alunos e ter uma boa didática mostrando a seus alunos os fenômenos
que ocorrem para que eles tenham interesse de querer adquirir mais conhecimento sobre a área e seu
professor deve ser capacitado para isso, para que seus alunos desenvolvam interesse pela química e
deem continuidade às pesquisas porque a quimica é uma ciência muito interessante [KPE1.1].

Ter didática, ou não, consiste em argumento, por parte dos alunos, para justificar o fato de o professor ser bom ou não. Porém, a definição de didática se restringe, na maioria das concepções, apenas, ao processo de ensino e aprendizagem. Desconsiderando, assim, outras dimensões correlatas a mesma como as questões epistemológicas e psicológicas. Sendo assim compreendemos como relevante problematizar alguns pontos no que se refere a esse processo de argumentação, embasado por esse critério. Primeiramente, precisamos oportunizar a nossos licenciandos compreender o que é didática, que aspectos a constituem e quais suas dimensões para além dos processos de ensinar e aprender.

Muitos cursos de Licenciatura em Química ou Ciências apresentam em sua estrutura curricular o componente de Didática, porém, o mesmo, recorrentemente, é ofertado por faculdades ou institutos de Educação, não ficando sob a responsabilidade de profissionais da área de Ensino de Química ou Ciências. Com o progresso de pesquisas e formação de profissionais na área de Educação em Ciências parece-nos pertinente que as matrizes curriculares adotem espaços 
nos quais a Didática específica possa ser assumida. Carvalho e Gil-Pérez (2011) argumentam sobre a relevância dos cursos de Licenciatura, na área de Ciências, assumirem a didática específica da sua formação como núcleo articulador de todo percurso formativo.

Leal (2009) produziu uma obra interessante no qual apresenta fundamentos e práticas referentes a didática da Química no Ensino Médio, pontuando aspectos particulares referentes ao ensino e aprendizagem, seu currículo e as abordagens metodológicas. $\mathrm{O}$ autor argumenta que a didática da Química engloba pelo menos três dimensões de reflexão, das quais cita: a epistemológica, a psicológica e a pedagógica. Argumenta que “a busca de um sentido escolar para a Química, a concepção de sentidos e modos de fazer essa Química escolar, é o propósito de uma didática própria” (LEAL, 2009, p. 10).

Acerca do atributo "ter didática", como constituinte do perfil do bom professor, destacado por KP, Cândido et al (2014) ao realizarem um estudo acerca da representação social do "bom professor" também identificam esta como uma característica sinalizada pelos sujeitos de pesquisa. Ao aplicar um questionário a duzentos e noventa e quatro acadêmicos de distintos cursos de graduação o predicado, relacionado ao ser bom professor, com maior percentual é o ser didático, seguido de ter bom relacionamento interpessoal e preocupar-se com alunos. Segundo os autores o aspecto ser didático, destacado pelos graduandos, se refere "à técnica utilizada pelos professores na tentativa de alcançar os objetivos que norteiam a intervenção pedagógica” (CÂNDIDO et al, 2014, p. 360).

Em pesquisa similar Machado, Azevedo e Freire (2013) buscaram delinear as condutas profissionais do "bom professor" por meio das respostas de duzentos e vinte graduandos de um curso de Pedagogia a um questionário. Assim como Cândido et al (2014), as autoras encontraram a característica ser didático, como elemento estruturante do perfil da representação de bom professor. Segundo as autoras, a partir do olhar dos sujeitos de pesquisa "o "bom" professor é dedicado, responsável, assíduo, competente, experiente, ético, compreensivo, tem sabedoria, conhecimento, didática e respeito aos alunos" (MACHADO, AZEVEDO e FREIRE, 2013, p. 332).

No entanto, ainda sobre a escrita de KP podemos adentrar em outro ponto, parece haver uma certa responsabilização do professor pelo processo de aprendizagem. Ou seja, aprendo porque o professor tem boa didática, e esse parece ser o único fator de relevância. Não podemos desconsiderar o fato de que aprender é um processo que contempla pelo menos três dimensões, o professor, o aluno e o conhecimento. Compreendendo o professor como mediador da relação aluno e conhecimento (BECKER, 2013).

Nesse movimento compreensivo, o interesse dos alunos é destacado pela licencianda como algo a ser desenvolvido pelo professor, especialmente quando menciona: "para que seus alunos desenvolvam interesse pela química e deem continuidade às pesquisas". Novamente a responsabilidade pela aprendizagem é atribuída ao professor, nesse momento agora no formato de "desenvolver o interesse".

Atribuir ao professor o papel de único responsável pela aprendizagem dos alunos não parece muito justo, mas os licenciandos ainda olham para essa questão apenas com lentes de aluno. Quando passam a assumir atividades de regência 
começam a problematizar as posturas dos alunos e cobram sua participação no processo de ensinar e aprender. É, de certa forma, um desvelamento da realidade. A forma de perceber o papel do professor assume outras perspectivas, amplia-se a percepção da realidade.

A nuance que percebe o professor como constante aprendiz de seu ofício é corroborada pela licencianda AF. Ela argumenta que o professor precisa estar em constante processo de aprendizagem, pois sua função promove a formação de futuros cidadãos, nas suas palavras:

Serprofessor de quimica é estar preparado para exercer seu papel com responsabilidade e competência se aprimorando no conteúdo a ser ensinado e dominando métodos e técnicas de ensino para chamar a atenção de seus alunos tendo assim um papel importante para a formação de indivíduos capazes de contribuir com a sociedade utilizando os conhecimentos e formação adquiridos na escola [AFE1.1].

A expressão utilizada pela licencianda, "formação de individuos capazes de contribuir com a sociedade" tem permeado a fala dos licenciandos, assumindo, de forma recorrente, outras configurações como: formar cidadãos, formar para atuar na sociedade, formar para cidadania, formar cidadãos críticos, entre outros. São apropriações, mesmo que sem maior compreensão, dos discursos perpetuados na área da Educação em Ciências e Química. No entanto, precisamos problematizar esses discursos, muitas vezes, mecanicamente replicados pelos licenciandos sem maior aprofundamento de seus pressupostos teóricos e metodológicos.

Ante o exposto, entendemos que mais do que conhecer e identificar um apanhado de estratégias metodológicas, ou mesmo desenvolver inúmeras propostas, compreender seus fundamentos parece mais relevante quando consideramos o contexto da formação de professores. Nesse sentido, nos ancoramos no que discorrem Vieira e Tenreiro-Vieira (2015) quando argumentam que mais do que definir uma estratégia como mais ou menos promotora do PC, precisamos nos focar na sua orientação e natureza.

É preciso analisar e problematizar o que é formar para cidadania, que pilares teóricos edificam essa perspectiva e que estratégias didáticas se configuram com maior potencial para essa finalidade. Argumentamos que, ao realizar esse tipo de exercício, com os licenciandos, podemos ampliar seu espectro de compreensão acerca da dimensão prática na ação docente. Nesse sentido, espaços como o da PCC se delineiam como potentes nesse processo, além de valorizar os saberes de interface que constituem os cursos de Licenciatura em Química.

Outra nuance destacada pelos licenciandos se refere à necessária articulação dos distintos saberes na ação pedagógica. Segundo o licenciando AT, um bom professor precisa ter distintos conhecimentos, dentre eles os pedagógicos, em suas palavras:

[...] um bom professor de quimica deverá ser conhecedor tanto da ciência a qual ensina, da teoria e da bistória de sua matéria e ter embasamento pedagógico para fazer se permitir passar o conbecimento. Porém, isso não é o que acontece pois temos uma educação básica precária e indiferente e uma graduação onde muitos professores sequer tiveram embasamento pedagógico [ATE1.2]. 
Considerando que AT é um aluno de segundo semestre, surpreende o fato de em seu argumento sobre o que é ser professor se fazer presente a compreensão da relevância e necessidade de o professor possuir um arcabouço de saberes que não contemple apenas os referentes a química. Em parte, tal percepção, mais complexa, sobre ser professor pode ser proveniente do fato de ser filho de professor.

Massi (2013) desenvolveu uma pesquisa na qual investiga a relação entre instituição e aluno em um curso de Licenciatura em Química e argumenta que alunos de primeira geração, com pais que não têm nível superior, apresentam maior dificuldade em articular as vivências no âmbito acadêmico às do cotidiano familiar, pois se torna complexo o estabelecimento do diálogo ante os enfrentamentos experienciados pelo estudante. Os pais não conseguem compreender os desafios que perpassam a vida acadêmica e o estudante sente dificuldades em fazer a ponte que potencializaria a conexão, tais aspectos acabam prejudicando a permanência destes alunos no curso.

Nessa conjuntura, além de conseguir, mais facilmente, estabelecer um diálogo acerca dos enfrentamentos do trajeto inerente à formação na Educação Superior, o núcleo familiar de AT oportuniza ao mesmo um espaço para complexificação dos desafios e elementos que constituem sua futura profissão. O que possibilita ao mesmo a constituição de uma compreensão mais ampla e consistente sobre ser professor.

Ao final da unidade de significado, podemos observar outra importante problematização elucidada por AT: "[...] temos uma educação básica precária e indiferente e uma graduação onde muitos professores sequer tiveram embasamento pedagógico". Além de questionar o status do sistema educacional de nível básico, também problematiza o que vivencia atualmente, o Ensino Superior. Sendo assim, novamente recaímos na questão supracitada, a didática dos professores.

Muitos professores formadores não vivenciaram o espaço do curso de licenciatura como alunos, assumem a função de docentes muito mais interessados em desenvolver pesquisa do que na sua atuação pedagógica. O que dizer ainda sobre a extensão, pouco desenvolvida em muitas áreas. Porém, em um curso de licenciatura todos atuam e devem ser responsáveis pela formação do profissional professor, como elucidam Mohr e Wielewicki (2017), nessa conjectura problematizar e propor ações que busquem articular as diferentes áreas que estruturam a matriz curricular do curso figuram como enfrentamentos a serem realizados e realidades a serem ampliadas.

Com o progresso das discussões no componente de BTA I as problematizações, acerca do que é ser professor de química, se direcionaram mais efusivamente para as teorias da aprendizagem. Na aula em que os aspectos inerentes à abordagem tradicional foram foco da discussão, algumas compreensões começaram a aflorar e ser problematizadas.

Ao analisar os princípios que constituem uma abordagem tradicional, $\mathrm{AC}$ e AF, em uma escrita coletiva destacam: "A abordagem tradicional de ensino é fundamentada em uma prática educativa centrada no professor, onde os alunos apenas escutam as prescrições que lhes são fornecidas por autoridades exteriores" [AC+AFE5.1].

A reflexão construída pelas licenciandas AC e AF oportuniza a percepção de que, ao assumir uma postura transmissiva de ensino, na qual a relação professor e aluno se verticaliza, apostas como a contextualização, mediação, diálogo e 
desenvolvimento do PC como princípios fundantes no processo de ensino e aprendizagem se deterioram. Como contextualizar sem investigar os conhecimentos prévios? Como investigar e mediar sem dialogar? Como desenvolver o PC em uma perspectiva de ensino por transmissão?

Diante desse cenário, Vieira e Tenreiro-Vieira (2015) argumentam sobre a relevância do desenvolvimento de pesquisas sobre a produção de estratégias que objetivem a promoção de capacidades de PC, porém, com a mínima aproximação a perspectivas orientadas pela transmissão de conhecimentos. A ênfase da transmissão que exige a memorização e a evocação mecânica de conhecimentos é destacada por Tenreiro-Vieira e Vieira (2001) como um elemento limitante no desenvolvimento do PC. Tenreiro-Vieira (2000, p. 47) argumenta que "a formação de alunos capazes de manifestarem e utilizarem o Pensamento Crítico é incompatível com professores transmissores".

Além do que foi destacado até então, AT chama atenção para o processo de desvalorização da carreira do professor e a realidade constituída por um sistema falho de ensino, nas suas palavras:

Atualmente, o que mais se vê em relação à profissão de professor é uma desvalorização e uma opinião alheia cercada de preconceitos para com a carreira. Apesar disso, cada área do conhecimento apesar de serem importantes como um todo, sofrem entre si com um sistema brasileiro falho de ensino [ATE1.1].

A desvalorização da carreira docente tem esvaziado os cursos de licenciatura, poucos alunos concluintes do Ensino Médio apresentam interesse por essa profissão. Tartuce, Nunes e Almeida (2010, p. 445) ao investigarem a atratividade da carreira docente, a partir do olhar de alunos concluintes do Ensino Médio, elucidam que os principais aspectos sinalizados pelos sujeitos de pesquisa como não atrativos são: "a ausência de identificação pessoal com a docência, as condições sociais e financeiras de exercício da profissão, a própria experiência escolar dos alunos e a influência familiar". Em um universo de um mil quinhentos e um entrevistados, apenas trinta e um, ou seja, 2\% dos alunos respondentes, colocaram como primeira opção o interesse em cursar uma licenciatura.

Nesse cenário, os fatores que provocam o desinteresse pela profissão se organizam em três grupos, dos quais podemos citar: os extrínsecos, os intrínsecos e os de ordem pessoal. Dos fatores extrínsecos, a baixa remuneração representa o percentual mais acentuado, no que se refere à não atratividade pela carreira docente, nos intrínsecos a exigência de envolvimento pessoal na profissão emerge como entrave. Já nos fatores de ordem pessoal o fato de não perceberem em si características inerentes à profissão docente se configuram como aspectos limitantes para escolha. Essas características se referem a uma compreensão que percebe a docência como dom e/ou vocação, logo os estudantes que não percebem em si esta espécie de capacidade, não se compreendem como potenciais professores (TARTUCE, NUNES e ALMEIDA, 2010).

De forma geral, as compreensões vinculadas ao ser professor de Química se alicerçam em algumas questões já reforçadas por teóricos do campo da formação de professores, como a percepção da formação como um processo contínuo, permeado pela constante busca por aprender mais. Além de outras nuances, referentes a 
aspectos atinentes ao ensinar e aprender, como a relevância da contextualização e do trabalho a partir do conhecimento prévio dos alunos. Ser professor de Química, a partir da perspectiva dos licenciandos que participaram de nossa investigação, envolve um processo contínuo de formação, buscando articular os diferentes saberes que compõem sua área em um exercício diário de pensar os processos inerentes ao ensinar e aprender, que englobam a relação professor e aluno.

\section{ESTRATÉGIAS QUE INTENCIONEM PROMOVER O PC E O PERFIL DE PENSADOR CRÍTICO QUE SE ALMEJA: UMA RELAÇÃO NECESSÁRIA}

Quando desafiados a escrever em seu portfólio sobre o que seria PC, os licenciandos utilizaram de uma estratégia que nos pareceu bem coerente, descreveram como seriam as características de uma pessoa que teria esse tipo de pensamento. Nesse movimento, o perfil do pensador crítico, segundo a análise dos licenciandos, envolve essencialmente autoquestionamento e curiosidade.

Estratégia similar foi utilizada por licenciandos ao serem desafiados a traçar uma definição acerca das características que envolvem o PC na investigação descrita por CALIXTO et al. (2017). Os autores sinalizam que, sob a ótica de análise das escritas dos sujeitos da pesquisa, o PC se configura como um potente elemento no desvelamento da realidade por meio de quatro processos, dos quais citam: de olhar e problematizar a realidade, questionar verdades estáticas, orientar-se pela racionalidade na observação e buscar soluções para problemas e tomar decisões.

Em uma primeira dimensão de definição alguns licenciandos pontuaram que pensar de forma crítica envolve análise e avaliação de ações cotidianas. Para AC ter "PC é avaliar e analisar nossos raciocinios, principalmente os da nossa vida do dia a dia" [ACE1.4]. KP segue uma linha de raciocínio similar e discorre que o PC se trata de um tipo de julgamento diante de nossas experiências diárias fundamentando assim nossas ações. Nas suas palavras "[...] o pensamento crítico é um tipo de julgamento propositado sobre o que acreditar ou fazer em resposta a uma experiência, aliás o pensamento crítico exige clareza [...]" [KPE1.2].

Tenreiro-Vieira e Vieira (2001) pontuam que, de forma recorrente, aspectos como racionalidade, reflexão e avaliação são destacados como características do PC. Estes aspectos são contemplados nas escritas das licenciandas acima, especialmente, quando pontuam que o PC envolve a dimensão da racionalidade e da avaliação, sempre correlacionando-as a uma determinada ação.

Em outra zona complementar de definição, alguns licenciandos definem o PC como um exercício de escuta de diferentes pontos de vista e autoquestionamento, pontuando que ter PC envolve um exercício de escuta, estudo e pesquisa. AQ discorre que o PC envolve um movimento que engloba considerar diferentes pontos de vista, em suas palavras: "O pensamento crítico quanto ao sujeito é quando você ouve, estuda e pesquisa sobre o que vai defender, e a partir de vários pontos e ideias cria e defende seu próprio pensamento" [AQE1.2]. BN adota uma linha de discussão próxima a de AQ e pondera que: "O senso crítico estimula o estudante a questionar e buscar as respostas das situações apresentadas, assim ele cria sua própria opinião, sem se basear no conbecimento de senso comum" [BNE1.2].

AF também corrobora da definição tecida por AQ e BN no sentido em que considera que alunos que têm PC são curiosos e buscam pontos de vista 
diferentes, como pode ser evidenciado a seguir: "Alunos que possuem pensamento crítico tem como característica a curiosidade e o anseio por pontos de vista diferentes sobre determinado assunto" [AFE1.2].

As linhas de discussão tecidas pelas licenciandas apresentam similaridades no sentido em que atribuem ao PC um modo de pensar dialógico, ou seja, que considera outras opiniões sobre a questão em pauta. Essa nuance é abordada por teóricos que estudam o PC como Paul e Elder (2008), ao buscarem delinear o que configurasse como PC discorrem sobre duas tipificações do mesmo, o fraco e o forte. Sendo o fraco constituído por uma forma de pensar monológica, caracterizada por um único ponto de vista. Já o forte se constitui por um modo de pensar dialógico, considerando assim vários pontos de vista.

Ao escreverem sobre o perfil do pensador crítico, as licenciandas adotam uma abordagem na qual a presença de um modo de pensar que considere outros pontos de vista, ou seja, outras formas de perceber a questão em pauta, se faz presente. Esse entendimento se aproxima a compreensões de teóricos como Paul e Elder (2008), já comentado, mas também às compreensões de outros como Ennis (1987), Tenreiro-Vieira (2000) e Vieira (2003).

Ao propor que o PC envolve uma prática reflexiva centrada no que acreditar e fazer, Ennis (1987) também argumenta sobre a relevância de considerarmos outros entendimentos acerca das decisões a serem tomadas. Em sua taxonomia, capacidades que nos levam a esse entendimento, são sinalizadas em todas quatro áreas básicas denominadas de clarificação elementar e elaborada, suporte básico, inferência e estratégias e táticas. No mesmo movimento Tenreiro-Vieira (2000) e Vieira (2003), ao se ancorarem nas compreensões de Ennis, argumentam sobre a relevância do PC como potência na análise de argumentos e da gama de informações que são disponibilizadas no contexto contemporâneo.

Por meio das escritas dos licenciandos acerca do perfil do pensador crítico compreendemos que este envolve autoquestionamento e curiosidade, mas não qualquer tipo de curiosidade e sim uma que se delineia epistemológica, como define Freire (1996). Esse ponto de discussão, em parte, pode se aproximar das discussões tecidas pelos licenciandos quando argumentam que o professor precisa desenvolver o interesse dos alunos, sendo que esse pode ser entendido como curiosidade, mas não qualquer tipo de curiosidade e sim uma que se caracterize pela busca em conhecer, ou seja, uma curiosidade epistemológica.

Mas, para além de pensarmos no perfil de uma pessoa com PC, precisamos considerar, analisar e avaliar as estratégias didáticas e suas potencialidades na promoção deste tipo de pensamento. De forma recorrente as escritas dos licenciandos pontuaram que as estratégias que objetivam promover o PC englobam debates, questionamento, resolução de problemas e tomada de decisão.

A vertente que atribui ao PC a potencialidade de tomada de decisões, frente a questões atuais no contexto de globalização, é exposta por AC e AF na escrita a seguir: "[...] vivemos em um mundo em que sempre estamos sendo desafiados a termos que estar prontos. Uso da capacidade de pensamento crítico permite aos indivíduos tomarem posiçôes sobre questões cientificas e atuais" [AC+AFE4.2].

A reflexão desenvolvida por $\mathrm{AC}$ e $\mathrm{AF}$, quando consideram a relação entre PC e o contexto contemporâneo, se aproxima do argumento tecido por Tenreiro- 
Vieira e Viera (2001, p. 14), no qual os autores pontuam que o PC “[...] é uma pedra basilar na formação de indivíduos capazes de enfrentarem e lidarem com a alteração contínua dos cada vez mais complexos sistemas que caracterizam o mundo atual".

Diante desse cenário, ao elaborar planejamentos que tencionem desenvolver o PC é preciso analisar e avaliar quais estratégias se configuram com maior potencialidade para esta finalidade. Vieira e Tenreiro-Vieira (2015) destacam que estratégias como a aprendizagem baseada em problemas e debates têm sido desenvolvidas com o objetivo da promoção do PC, ambas têm apresentado resultados significativos no que concerne a esse intento. Além de reforçarem o argumento acerca da relevância das estratégias se orientarem de forma explícita no objetivo de promoção de capacidades e disposições de PC.

No que se refere aos planos de aula, elaborados pelos licenciandos, em sua totalidade se fundamentaram nos pressupostos da teoria da aprendizagem humanista e propuseram o trabalho com duas possibilidades, em termos de estratégias didáticas, das quais podemos citar: experimentação e resolução de problemas. Sendo ambas constituídas por movimentos que envolviam o questionamento como elemento promotor do desenvolvimento do PC.

AQ e AT sugeriram, em seu plano de aula, o desenvolvimento de um experimento sobre Termoquímica, o mesmo consiste na manipulação de dois balões, do tipo de festa de aniversário, sobre a chama de uma vela. O balão A contendo em seu interior apenas ar e o balão B por ar mais aproximadamente 150 $\mathrm{mL}$ de água. Ao colocarem ambos balões sobre a chama da vela observa-se que o balão A estoura enquanto o B não. Nesse sentido, os questionamentos promotores do PC, segundo a ótica dos licenciandos, são os seguintes: "Explique por que o balão que tinha apenas ar estourou; Explique por que o balão que tinha água e ar não estourou; Qual a finalidade desse experimento?' [Plano de Aula de AQ+AT].

Por meio dessas perguntas, AQ e AT, consideram que podem ser desenvolvidas capacidades, descritas por Ennis em sua taxonomia do PC, ${ }^{4}$ como: identificar conclusões; resumir; observação; explicar e formular hipóteses, e; conclusões das ações propostas. Estas capacidades se alocam nas áreas denominadas por Ennis como clarificação elementar, suporte básico e inferência.

No entanto, em seu planejamento os licenciandos não consideraram a necessidade de outros questionamentos na construção do conhecimento dos alunos. Para complexificar e articular os conhecimentos desenvolvidos, a ação mediadora do professor seria de extrema relevância nesse percurso. Como poucas questões, sem o auxílio de inúmeras outras subquestões, poderiam desenvolver essa amplitude de capacidades?

BN e KP, em seu plano de aula, propõem uma atividade organizada a partir de duas situações que envolviam a resolução de problemas que trabalhariam conceitos de funções inorgânicas, das quais podem ser observadas a seguir:

$1^{\circ}$ Problema: Ao ir tomar banho e ligar o chuveiro você percebe que está saindo pouca água, que os buracos do chuveiro estão entupidos. O que causa este problema? O que pode ser feito e porquê? Além de esboçar a fórmula das substâncias envolvidas na problematização faça sua nomenclatura. $2^{\circ}$ Problema: Uma pessoa está sentindo fortes dores estomacais, ao procurar um médico é diagnosticada com gastrite. 
Qual conteúdo estomacal que quando está em excesso no estômago gera este problema? Qual a fórmula e o nome do conteúdo que provoca queimação no estômago? [Plano de Aula de $\mathrm{BN}+\mathrm{KP}$ ].

Como capacidades exigidas para resolução dos problemas apresentados são destacadas: focar uma questão; fazer e responder a questões de clarificação e desafio; além de decisões sobre uma ação. Estas capacidades se encontram localizadas em áreas denominadas por Ennis como clarificação elementar e estratégias e táticas. Porém, ao propor tais questionamentos, as licenciandas não consideraram o fato de que o ponto de maior ênfase, na defesa do seu planejamento, concentrou-se nos alunos conseguirem ou não expressar a fórmula correta dos compostos solicitados ao final das questões e não na compreensão e análise da situação como um todo.

AC e AF, em seu planejamento, sugerem o trabalho com um experimento que envolvia conceitos de propriedades da matéria, mais especificamente a densidade. O mesmo consiste na imersão de cubos de gelo a dois copos, o primeiro contendo água e o segundo álcool. Como questionamentos orientadores na observação as licenciandas propõem: "Por que o gelo afunda no álcool e na água não?; O que é densidade?; Porque o gelo é menos denso que a água?; O tamanho do material influencia em sua densidade?" [Plano de Aula de AC+AF].

Como capacidades exigidas sinalizam: focar uma questão e decisões sobre uma ação, o que contempla duas áreas, clarificação elementar e estratégias e táticas. Ao analisar os planejamentos, podemos perceber que todos contemplam a área denominada por Ennis de estratégias e táticas, em parte, podemos atribuir essa similaridade ao fato desta ser a primeira das áreas que compõem a taxonomia. Fator que pode fixar a atenção dos licenciandos neste espaço, não destinando maior atenção as áreas subsequentes. ${ }^{5}$

Nesse sentido, percebemos um avanço no movimento em que os licenciandos, apesar das limitações, conseguiram desenvolver um planejamento que apresentava em sua estrutura fundante a participação ativa dos alunos e que almejava desenvolver um diálogo profícuo entre professor e aluno. No entanto, a compreensão do diálogo como ferramenta na construção do conhecimento, ou seja, como possível elemento na passagem da curiosidade ingênua para a epistemológica ainda não foi totalmente entendida pelos licenciandos.

Apesar do questionamento ser sinalizado em todos os planos de aula como elemento promotor do PC, associado a uma estratégia mais ampla como experimento ou resolução de problemas, a qualidade deste não foi tão significativa. Em sua maioria se configurava como meio para reprodução de conhecimentos esperados pelo professor. As limitações na elaboração dos planejamentos desenvolvidos pelos licenciandos, em parte, repercutem as carências que a proposta de ensino do componente de BTA I apresentou. Como alternativa para minimizar estas lacunas, concernentes ao trabalho com questionamento, poderiam ter sido apresentados aos licenciandos trabalhos com abordagem FRISCO, ${ }^{6}$ por exemplo. Sinalizada por Vieira e Tenreiro-Vieira (2005) como boa alternativa no trabalho com questionamento que objetive promover o PC. No que se refere a proposta orientada pela resolução de problemas, trabalhos com um planejamento mais detalhado das etapas que constituem a resolução do mesmo e com natureza mais explícita, no intento do desenvolvimento do PC, poderiam ser abordados. 


\section{COMPREENSÕES EMERGENTES}

O exercício de análise e compreensão desenvolvido oportunizou a emergência de algumas pistas acerca do processo de constituição do ser professor de química no espaço de um componente curricular com carga horária integralmente destinada a PCC. Dentre estas, aflora a compreensão de que a complexificação dos saberes inerentes à ação docente pode estar fortemente vinculada ao estabelecimento de uma maior coerência entre o entendimento dos modos de ensinar e aprender as questões mais inconscientes dos licenciandos sobre ser professor. Por meio desse movimento se oportuniza um desvelamento das estruturas mais subjetivas que compõem o entendimento sobre ser professor, nesse contexto se potencializa uma profícua articulação entre o saber e o fazer de forma consciente e coerente.

Ancorados por essa compreensão argumentamos em prol do desenvolvimento de estratégias didáticas que promovam, no espaço da formação inicial, um movimento de desestabilização dos processos de conservação da realidade dos licenciandos nos quais são fortificadas visões distorcidas sobre ser professor e dos processos inerentes ao ensinar e aprender. Nesse ínterim, para que metas como essa possam ser alcançadas é imprescindível que o isomorfismo entre a formação ofertada e a exigida possam encontrar uma coesão profícua. Espaços como os oportunizados pela PCC e pelos Estágios são essenciais nesse movimento, mas não podem ser compreendidos como únicos responsáveis. Todas as áreas que compõem o curso, constituídas por seus diferentes saberes, precisam estar articuladas e estabelecer um diálogo produtivo, tendo como meta conjunta a constituição do ser professor.

Por meio da análise das escritas dos portfólios e dos planos de aula, referente ao componente foco do estudo de caso, compreendemos que a elaboração de um planejamento orientado para a promoção do PC oportunizou aos licenciandos o desafio de romper com modelos que se orientem por propostas de ensino por transmissão. Proporcionando aos mesmos um contexto formativo propício ao desenvolvimento de uma crítica fundamentada à perspectiva transmissiva de ensino, sendo esta estruturada a partir da análise dos fundamentos correlatos a teorias da aprendizagem.

\section{REFERÊNCIAS}

ALMEIDA, S. A. Prática como Componente Curricular nos cursos de formação de professores de Química no Estado de Goiás. 2016. Dissertação (Mestrado em Educação em Ciências e Matemática), Universidade Federal de Goiás-UFG, Goiânia-MG, 2016.

BARBOSA, A. T.; CASSINI, S. Sentidos da prática como componente curricular nos documentos do conselho nacional de educação. Revista SBENBIO, n.7, p. 195-204, out., 2014.

BECKER, F. A epistemologia do professor: o cotidiano da escola. 16ª ed. Petrópolis, RJ: Vozes, 2013. BERGER, P.; LUCKMANN, T. A construção social da realidade. 22ª ed. Petrópolis, RJ: Vozes, 2002. 
BRASIL. Conselho Pleno. Resolução CNE/CP 02/2002 de 19 de fevereiro de 2002. Institui a duração e a carga horária dos cursos de licenciatura, de graduação plena, de Formação de Professores da Educação Básica em nível superior. 2002.

BRASIL. Conselho Pleno. Resolução CNE/CP 02/2015 de 01 de julho de 2015. Define as Diretrizes Curriculares Nacionais para a formação inicial em nível superior (cursos de licenciatura, cursos de formação pedagógica para graduados e cursos de segunda licenciatura) e para a formação continuada. 2015.

BRASIL. Projeto Pedagógico do Curso de Licenciatura em Química. Universidade Federal da Grande Dourados. Dourados, 2017.

CALIXTO, V. S.; BORDONI, A. J.; TAKAHASHI, D. A. G.; KIOURANIS, N. M. M.; SILVEIRA, M. P. da. Compreensões de licenciand@s em Química acerca do Pensamento Crítico: um possível horizonte interpretativo. ACTIO, Curitiba, v. 2, n. 1, jan.-jul., p. 184-203, 2017. Disponível em: $<$ https://periodicos.utfpr.edu.br/actio>.

CALIXTO, V. S. Horizontes compreensivos da constituição do ser professor de Química no espaço da prática como componente curricular. (Tese de Doutorado). Centro de Ciências Exatas, Universidade Estadual de Maringá, Maringá, Brasil. 2019.

CÂNDIDO, C. M.; ASSIS, M. R.; FERREIRA, N. T.; SOUZA, M. A. a representação social do "bom professor" no Ensino Superior. Psicologia \& Sociedade, v. 26, n. 2, p. 356-365, 2014.

CARvalho, A. M. P.; GIL-PÉREZ, D. Formação de Professores de Ciências: tendências e inovações. 10 ed. São Paulo: Cortez, 2011.

CUNHA, M. I. Docência na Educação Superior: a professoralidade em construção. Educação (Porto Alegre), v. 41, n. 1, p. 6-11, jan-abr., 2018.

DINIZ-PEREIRA, J. E. A prática como componente curricular na formação de professores. Educação, Santa Maria, v. 36, n. 2, p. 203-218, maio/ago., 2011.

ENNIS, R. H. A taxonomy of critical thinking dispositions and habilities. In J. B. Baron e R. J Sternberg (ed.). Teaching Thinking skills: Theory and practice. New York: W. H. Freeman and Company, 1987.

ENNIS, R. H. Critical thinking dispositions: Their nature and assessability. Informal Logic. v.18, p. 165-182, 1996.

FREIRE, P. Pedagogia do oprimido. 59ª ed. Rio de Janeiro: Paz e Terra, 2016.

HALPERN, D. F. Thought and Knowledge - An introduction to critical thinking. New Jersey, Editora Lawrence Erlbaum Associates, 1989.

KASSEBOEHMER, A. C.; FARIAS, S. A. Conteúdos das Disciplinas de Interface Atribuídos a Prática como Componente Curricular em Cursos de Licenciatura em Química. ALEXANDRIA: Revista de Educação em Ciência e Tecnologia, v. 5, n. 2, p.95-123, set., 2012.

LEAL, M. C. Didática da Química: fundamentos e práticas para o Ensino Médio. Belo Horizonte: Dimensão, 2009.

MACHADO, L. B.; AZEVEDO, M. F.; FREIRE, S. B. O "bom" professor universitário nas representações sociais de estudantes de pedagogia. Roteiro, Joaçaba, v. 38, n. 2, p. 311-336, jul.-dez., 2013. 
Horizontes compreensivos da constituição do ser professor de química no espaço da prática como componente curricular: um estudo de caso

MARCELO-GARCÍA, C. Formação de Professores: para uma mudança educativa. Porto, Portugal: Editora Porto LDA, 1999.

MASSI, L. Relação aluno-instituição: o caso da licenciatura do Instituto de Química da UNESP/ Araraquara. 2013. Tese (doutorado) - Instituto de Física e Faculdade de Educação, Universidade de São Paulo, São Paulo, 2013.

MARTINS, J. L. C.; WENZEL, J. S. A prática de ensino na organização curricular dos cursos de química licenciatura: atenção para as $400 \mathrm{~h}$ de práticas de ensino. REVISTA DEBATES EM ENSINO DE QUÍMICA, v. 3, n. 2 p. 5-26, 2017.

MOHR, A.; WIELEWICKI, H. G. Prática como componente curricular: que novidade é essa 15 anos depois? Florianópolis: NUP/CED/UFSC, 2017.

MORAES, R.; GALIAZZI, M. C. Análise Textual Discursiva. Ijuí: Ed. Unijuí, 2016.

PAUL, R; ELDER, L. The thinker's guide to the nature and functions of Critical and Creative thinking. 1 ed. The Foundation for Critical Thinking, 2008.

PIMENTA, S. G. Professor reflexivo: construindo uma crítica. In: PIMENTA, S. G.; GHEDIN, E. Professor reflexivo no Brasil: gênese e crítica de um conceito. São Paulo: Cortez, 2006, p. 17-52.

PEREIRA, B.; MOHR, A. Origem e Contornos da Prática como Componente Curricular. In: MOHR, A.; WIELEWICKI, H. G. Prática como componente curricular: que novidade é essa 15 anos depois? Florianópolis: NUP/CED/UFSC, 2017, p. 19-38.

QUADROS, A. L.; CARVALHO, M.; COELHO, F. S.; SALVIANO, L.; GOMES, M. F. P. A.; MENDONÇA P. C.; BARBOSA, R. K. Os professores que tivemos e a formação da nossa identidade como docentes: um encontro com nossa memória. Ensaio: Pesquisa em Educação em Ciências, v.7, n.1, p. 4-11, jan-abr., 2005.

SILVÉRIO, L. E. R. As práticas pedagógicas e os saberes da docência na formação acadêmico-profissional em Ciências Biológicas. 2014. Tese (Doutorado em Educação Cientifica e Tecnológica) - Centro de Ciências Físicas e Tecnológicas, Universidade Federal de Santa Catarina, Florianópolis-SC, 2014.

TARTUCE, G. L. B. P.; NUNES, M. N. R.; ALMEIDA, P. C. A. Alunos do Ensino Médio e atratividade da carreira docente no Brasil. Cadernos de Pesquisa, v.40, n.140, p. 445-477, mai.-ago., 2010.

TENREIRO-VIEIRA, C. O pensamento crítico na Educação científica. Lisboa, Instituto Piaget, 2000.

TENREIRO-VIEIRA, C; VIEIRA, R. M. Promover o pensamento crítico dos alunos: propostas concretas para sala de aula. Porto: Porto editora, 2001.

VIEIRA, R. M. Formação Continuada de Professores do $1^{\circ}$ e $2^{\circ}$ Ciclos do Ensino Básico Para uma Educação em Ciências com Orientação CTS/PC. 2003. Tese (Doutorado em Didática) Departamento de Didáctica e Tecnologia Educativa, Universidade de Aveiro, Aveiro-Portugal, 2003.

VIEIRA, R. M.; TENREIRO-VIEIRA, C. Estratégias de ensino/aprendizagem: o questionamento promotor do pensamento crítico. Lisboa: Editorial do Instituto Piaget, 2005. 
VIEIRA, R. M.; TENREIRO-VIEIRA, C. Práticas didático-pedagógicas de ciências: Estratégias de ensino/aprendizagem promotoras do pensamento crítico. Saber \& educar. n. 20, p. 34-41, 2015.

YIN, R. K. Estudo de caso: planejamento e métodos. $5^{\text {a }}$ ed. Porto Alegre: Bookman, 2015.

ZEICHNER, K. M. Políticas de formação de professores nos Estados Unidos: como e por que elas afetam vários países do mundo. Belo Horizonte: Ed. Autêntica, 2013.

\section{NOTAS}

1 Realizamos a opção por apresentar nesse texto, apenas, a dimensão de análise referente a este componente diante do espaço que temos para discussão.

2 O número entre os parênteses se refere à quantidade de unidades de significado que constituem a categoria mencionada.

3 O código se organiza a partir do codinome do licenciando seguido de $\mathrm{E}$ mais um numeral, o que representa o número da escrita do portfólio. Por fim, ainda acrescentamos após o numeral um ponto e outro numeral, que representava se a escrita foi dividida em mais de uma unidade de significado. Sendo assim, o seguinte código (Codinome+E1.1) representa que a unidade de significado corresponde a primeira escrita do portfólio do licenciando X e a sua primeira unidade de significado.

4 A taxonomia do PC, elaborada por Ennis, poderá ser encontrada nas seguintes obras: Ennis (1987), Tenreiro-Vieira (2000), Vieira (2003) e Calixto (2019).

5 Cabe ressaltar que nosso objetivo, nessa investigação, não se centrou na correta adequação das questões às capacidades e disposições descritas na taxonomia proposta por Ennis, mas em compreender as potencialidades que a elaboração de um planejamento orientado para promoção do PC pode constituir ao propor o rompimento a modelos de ensino e aprendizagem centrados na transmissão de conhecimentos.

6 Esta abordagem configura-se como uma estratégia de questionamento, explicitamente, orientada para o PC, um exercício de operacionalização para o desenvolvimento das capacidades e disposições listadas por Ennis. Sendo estas questões estruturadas em seis momentos que tencionam oportunizar a tomada de decisões racionais, dos quais podemos citar: "(i) Foco; (ii) Razões; (iii) Inferências; (iv) Situação; (v) Clareza; e (vi) Overview — Visão global/ampla. Note-se que a designação FRISCO procura contemplar estes seis momentos, porquanto cada letra do acrónimo corresponde à inicial do termo que designa cada um deles" (VIEIRA e TENREIRO-VIERA, 2003, p. 237-238).

Submetido em 14/08/2019

Aprovado em 28/10/2019

Contato:

Rodovia Dourados - Itahum, Km 12

Caixa Postal -533

$3^{\circ}$ piso da FACET

CEP 79.804-970 - Dourados, MS - Brasil 